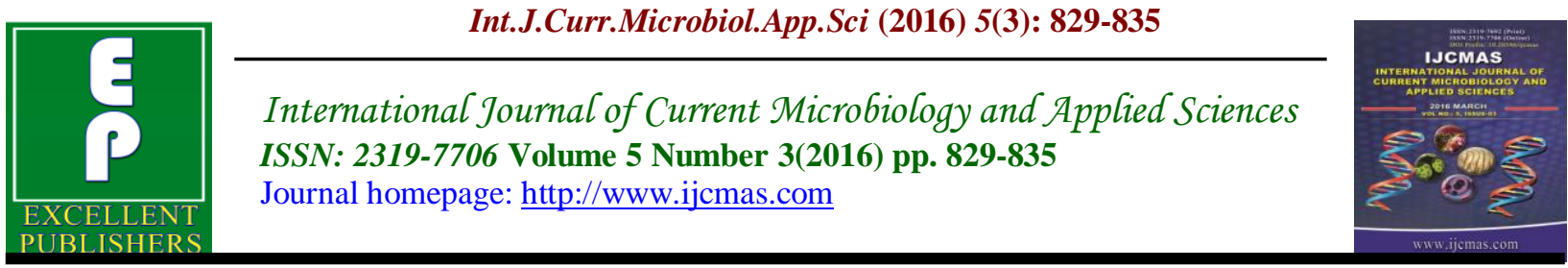

\title{
Utilization of the Fungus Duddingtonia flagrans in Control of Nematode Larvae Development in Equine Stool
}

\author{
Manuela Colares de Andrade ${ }^{1}$, Emy Hiura, Leandro Abreu da Fonseca ${ }^{2}$, Carolina Magri \\ Ferraz $^{1}$, Caio Colodette Senna ${ }^{1}$, Fabio Porto Sena ${ }^{1}$, Lorena Coutinho Correa ${ }^{1}$, Anderson \\ Rocha Aguiar', Tracy Ferreira Lacerda ${ }^{1}$, Fabricia Molodo Giradi ${ }^{2}$, Jackson Victor de \\ Araújo $^{2}$, Fernando Luis Tobias ${ }^{1}$ and Fabio Ribeiro Braga ${ }^{1}$. \\ ${ }^{1}$ Clinical and Veterinary Parasitology Laboratory, University Vila Velha, Espirito Santo, Brazil \\ ${ }^{2}$ Department of Veterinary Medicine, Federal University of Viçosa, Minas Gerais, Brazil \\ *Corresponding author
}

\section{Keywords \\ Stool, \\ Nematode, \\ Resistance, \\ Duddingtonia \\ flagrans and \\ Biological \\ Control}

\section{Article Info}

Accepted:

15 January 2016

Available Online:

10 March 2016

\section{A B S T R A C T}

Fecal environment in conjunction with the pastures act as a sort of "incubator" and reservoir propagator for infective larvae (L3) belonging to nematode parasites. In this sense, the use of antagonists that can act to control the development of nematodes in stool is welcome. In the present the nematophagous fungus Duddingtonia flagrans (AC001) was used. The objective of this study was to use the fungus Duddingtonia flagrans in the biological control of the development of nematode larvae in equine stool. Feces from parasited equine raised on pasture in a rural property in the south east region of Espirito Santo - Brazil were used during the months of July to August 2015. Then, the fecal samples were separated into two equidistant locations where they were divided into a control group and a group treated with fungus. Weekly, in the treated group, $2 \mathrm{~mL}$ of the fungus with an approximate concentration of 1,000 chlamydospores was added. In the control group $2 \mathrm{~mL}$ of distilled water was added. Next, from each stool sample, in each group, total fecal masses were collected for further analysis of EPG, stool cultures, and later the Baermann for L3 reduction analysis. The dynamics of the experiment was based on the addition of fungus and or distilled water, collection of total fecal mass, followed by replacement of the fecal boli from the treated and control groups with positive stool for equine gastrointestinal nematodes. The results demonstrated that the larvae mean counts for the control group were higher than the average L3 retrieved from the group treated with AC001 $(\mathrm{p}<0.01)$. The L3 reduction percentage retrieved from the group treated with AC001 was $48.2 \%$ in relation to the control group. The results of this study point to the need for further research to be carried out involving the biological control for nematode population dynamics in equine stool. 


\section{Introduction}

Horses raised on pasture favor the high incidence of parasitic infections, since the first weeks of life and among the sea large number of families/genera of gastro intestinal nematode parasites (Molento, 2005). The fecal environment in conjunction with the pastures, act as a sort of "incubator" and reservoir propagator for such parasites (Silva et al., 2008). The development of the larvae from the egg to the infective stage occurs usually from five to seven days. When inside the organism it develops into the adult phase.

Accordingly, Oliveira-Sequeira and Amarante (2001) mentions that most gastrointestinal nematode parasites reach the animals' organism through ingestion of contaminated pasture with third stage larvae (L3). The larva grows and changes twice before becoming infective, when it then migrates from inside the stool to the pastures about.

The worms cause production decrease which results in economic loss and direct damage to the horses' health.In adult animals the symptoms may appear less pronounced, although the overall performance is not satisfactory (Urquhart et al., 1998). Faced with this growing problem, horse owners and veterinarians must be increasingly attentive to the biology and epidemiology of parasitic diseases in order to develop a correct and appropriate animal health program, which in most cases can be integrated with the biological control of L3 in pastures (Milillo et al., 2009; Lyons et al., 2011; Braga et al., 2011; Tavela et al., 2013).

In relation to the context in production, Brazil is recognized as a global power in agribusiness and recently the Ministry of Agriculture Livestock and Supply
(Ministério da Agricultura Pecuária e Abastecimento) classified the Brazilian Equine-culture as part of the agribusiness sector due to its economic and social importance. Owning the largest herd of horses in Latin America and third largest in the world. Together with the mules and donkeys there are 8 million animals, moving $\mathrm{R} \$ 7.3$ billion, only with the production of horses (MAPA, 2015). However parasite control is still the bottle neck of this production.

The term biological control refers to the use of natural antagonists available in the environment, decreasing the population of a particular agent causing damage in the property (Bañolas et al., 2008). The parasite's resistance to anthelmintics is a real problem that affects farmers. This resistance is caused by an inappropriate use of anthelmintic drugs over the years. However, it should be mentioned that the control of gastrointestinal nematode parasites in horses aims to control the parasites in their parasitic phase and not their environmental phase, which makes biological control viable measure, since it aims to "attack and destroy" these parasites in the pasture (Paz Silva et al., 2011).

Duddingtonia flagrans is the species most studied in controlling of nematode parasites belonging to horses (Braga et al., 2015). It is a fungus that has great ability to produce chlamydospores in stool (Silva et al., 2013). This fungus has the ability to pass through the horse's gastrointestinal tract, germinating in the stool and be viable in the capturing of the gastrointestinal nematode parasite's L3 (Faedo et al., 1998; Fernadez et al., 1997). Waller (2001) considers the advantages of the nematophagous fungus $D$. flagrans in relation to others, due to their rapid growth rate, as well as its affinity to capture and digest nematodes. However, 
there aren't many studies in natural conditions which favor the use of this fungus directly into the stool of horses raised on pasture, being this a direct control strategy.

The objective of this study was to use the fungus Duddingtonia flagrans in the biological control of nematode larvae development in equine stool.

\section{Materials and Methods}

Feces from parasited equine raised on pasture in a rural property in the south east region of Espirito Santo - Brazil were used during the months of July to August 2015. Egg Count per gram of feces (EPG) was performed to quantify the parasite load. For possible realization of the following experiments, quantifying the parasite load was required, where the average ranged from 2450 to 2800 eggs and a Baerman average of 508 larvae.

A nematophagous fungi, Duddingtonia flagrans (AC001) isolate, originated from Brazilian soil, and derived from the Parasitology Laboratory of the Federal University of Viçosa (UFV) was used. The fungi were maintained at $4^{\circ} \mathrm{C}$ in test tubes containing $2 \%$ corn-meal-agar (2\% CMA) and kept in the dark for10 days. After the growth of the isolates, novel $4 \mathrm{~mm}$ in diameter culture dishes were transferred to Petri dishes of $9 \mathrm{~cm}$ in diameter containing $20 \mathrm{ml}$ of $2 \%$ water-agar (2\%WA) in which was added $1 \mathrm{~mL}$ of distilled water containing 1,000 Panagrellus sp larvae, a free-living nematode, daily over a period of 21 days to induce formation of fungal conidia. When complete fungal growth was observed, $5 \mathrm{ml}$ of distilled water was added to each Petri dish, and conidia and mycelial fragments were removed according to the technique described by Araújo et al. (1993).
Following, the fecal samples were separated into two equidistant locations where they were divided into four control groups and four groups treated with fungus. In each group there were four samples, totaling 32 samples. These locations were surrounded and protected with mosquito screen in order to prevent the entry and "trampling" of the animals (Figure 1).

Weekly, in the treated group, $2 \mathrm{~mL}$ of the fungus with an approximate concentration of 1,000 chlamydospores was added. In the control group $2 \mathrm{~mL}$ of distilled water was added.

Later, on a weekly basis, the total fecal mass was collected for stool analysis in the Clinical and Veterinary Parasitology Laboratory of the University Vila Velha, Baermann (1948). Next, from each stool sample, in each group, total fecal masses were collected for further analysis of EPG, stool cultures, and later the Baermann.

The dynamics of the experiment was based on the addition of fungus and or distilled water, collection of total fecal mass, followed by replacement of the fecal boli from the treated and control groups with positives tool for equine gastrointestinal nematodes.

The effectiveness of the fungus use was based on the EPG results and reduction of infective larvae through the use of the Baermann technique, using the following formula:

\section{Reduction \%}

Average L3 recovered from control group stool - Average L3 recovered from treated group stool x 100

Average L3 recovered from control group stool. 


\section{Statistical analysis}

L3 predation efficiency in the treated group (AC001) in relation to the control group was evaluated by the Tukey test at $1 \%$ probability.

\section{Results and Discussion}

In this study, the mean larvae counts for the control group were higher than the mean L3 recovered from the group treated with AC001 ( $\mathrm{p}<0.01)$ (Table 1 and Figure 1). The $\mathrm{L} 3$ reduction percentage recovered in the group treated with $\mathrm{AC} 001$ was $48.2 \%$ in relation to the control group. Accordingly, in the present study, and following the premise of Braga et al. (2010), biological control conducted with nematophagous fungi stands out as a promising alternative.

Table.1 Mean and standard deviation ( \pm ) of the recovered larvae from the stool of control group and groups treated with Duddingtonia flagrans

\begin{tabular}{rrrcc}
\hline Group & 1 & 2 & 3 & 4 \\
\hline AC001 & $59.5^{\mathrm{A}} \pm 24.0$ & $80.4^{\mathrm{A}} \pm 26.9$ & $32.7^{\mathrm{A}} \pm 13.9$ & $74.4^{\mathrm{A}} \pm 19.4$ \\
& & & & \\
Control & $112^{\mathrm{B}} \pm 25.4$ & $165.3^{\mathrm{B}} \pm 57.3$ & $74.9^{\mathrm{B}} \pm 19.6$ & $127.8^{\mathrm{B}} \pm 34.5$ \\
\hline
\end{tabular}

Means followed by different capital letters in the columns differ statistically $(\mathrm{p}<0.01)$ - Tukey test; AC001Duddingtonia flagrans

Figure.1 Stool from horses on pasture

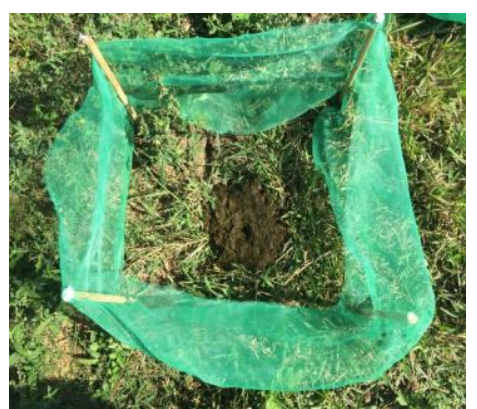

Studies have shown that nematophagous fungi do not cause imbalance in the environment. Yeates et al. (1997), offered blocks of the predator nematophagous fungus $D$. flagrans to sheep and treated another group with anthelmintic to check the effect of soil nematodes. The results showed that there were no significant changes in the nematode fauna in this environment. Likewise, Braga et al. (2009) conducted a pellets path test containing this fungus in

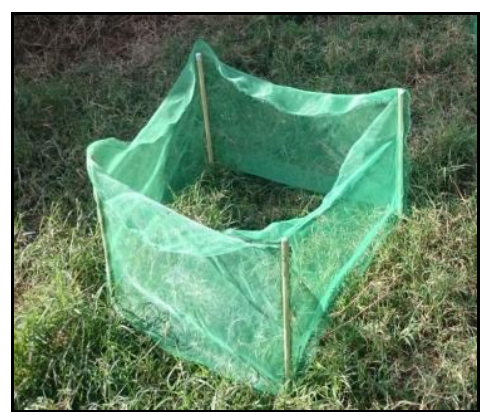

pasture raised horses for a period of eight months and found no environmental damage. In the present study, the authors suggest the effectiveness in the control of L3 belonging to equine nematode parasites directly from stool.

Comparing the findings of the present study, literature mentions that there are not many studies with the fungus $D$. flagrans (AC001) acting directly in the stool. In accordance 
with Madeira de Carvalho et al. (2007), D. flagrans administered in a daily dose of 5x105 spores/kg BW, showed a significant reduction of $62-72 \%$ in mean larval population and a significant decrease of 50$70 \%$ in strongyles L3 pasture contamination, which makes this control method very promising in grazing horses when associated with treatment with anthelmintics. In a study conducted by Almeida (2009), the total number of larvae recovered was higher in the control group during the months of November and December 2007 and January and February 2008 with larval reduction percentages of $30 \%, 7.2 \%, 22 \%$, and $24.2 \%$, respectively, compared to groups treated with the fungus $D$. flagrans.

Regarding the adverse effects that the fungus can cause, such as action on other organisms that are beneficial to the soil and the environment, in a study developed by Knox, Josh and Anderson (2002), it was seen that $D$. flagrans does not promote negative environmental impact when used in a pasture production system. These mentioned findings indicate that the results from the Baermann test in this study were expected, which corroborates with other authors that the fungus $D$. flagrans caused a significant reduction on free-living larvae.

Finally it is noteworthy that the epidemiological study of gastrointestinal nematode parasites belonging to horses deserves further study, since the development of these nematodes in the pasture is conditioned to several factors, among which the presence of antagonistic organisms such as the fungus Duddingtonia flagrans. The results of the present study point towards the development of further research concerning the biological control for nematode population dynamics in equine stool.

\section{References}

Almeida, G.L. 2009. Atividade predatória do fungo Duddingtonia flagrans sobre larvas infectantes de estrongilídeosparasitos de equinos na pastagem no sul doBrasil. Santa Maria: Universidade Federal de Santa Maria, Dissertação.

Araújo, J.V., Santos, M.A., Ferraz, S., Maia, A.S. 1993. Antagonistic effect of predacious Arthrobotrys fungi on infective Haemonchus placei larvae. $J$. Helm., 67: 136-138.

Bañolas, J.M., Morais, J.N., Rue, M.L.D.L. 2008. Duddingtonia flagrans: controle biológico de nematódeos de bovinos a campo. Ciência Rural., 38(8).

Braga, F.B., Araujo, J.M., Silva, A.R., Araújo, J.V., Carvalho, R.O., Tavela, A.O., Silva, M.E., Fernandes, F.M., Melo, A.L. 2011. Destruição de larvas infectantes de Strongyloides venezuelensis pelos fungos Duddingtonia flagrans, Arthrobotrys robusta e Monacrosporiumsinense. Revista da Sociedade Brasileira de Medicina, 44(3): 389-391.

Braga, F.R., Araújo, J.V., Silva, R.A., Araujo, J.M., Carvalho, R.O., Tavela, A.O., Campos, A.K., Carvalho, G.R. 2009. Biological control of horse cyathostomin Cyathostominae) using the nematophagous fungus Duddingtonia flagrans in tropical southeastern Brazil. Veterin. Parasitol., 163: 335-340.

Braga, F.R., Soares, F.E.F., Giuberti, T.Z., Lopes, A.D.C.G.L., Lacerda, T., Ayupe, T.H., Queiroz, P.V., Gouveia, A.S., Pinheiro, L.V., Araújo, A.L., Queiroz, J.H., Araújo, J.V. 2015. Nematocidal activity of extracellular enzymes produced by the nematophagous fungus Duddingtonia 
flagrans on cyathostomin infective larvae. Veter. Parasitol., Pp. $\mathrm{x}-\mathrm{x}$.

Braga, F.R., Araújo, J.V., Araujo, J.M., Silva, A.R., Carvalho, R.O., Ferreira, S.R., Benjamin, L.A. 2010. Predatory activity of the nematophagous fungus Duddingtonia flagrans on horse cyathostomin infective larvae. Trop. Anim. Health Prod., 42(6): 1161-1165.

Faedo, M., Barnes, E.H., Dobson, R.J., Waller, P.J. 1998. The potential of nematophagus fungi to control the freeliving stages of nematode parasites of sheep: pasture plot study with Duddingtonia flagrans. Veter. Parasitol., 76: 129-135.

Fernadez, A.S., Larsen, M., Nansen, P., Gronvold, J., Henricksen, S.A., Wolstrup, J. 1997. Effect of the nematode-trapping fungus Duddingtonia flagrans on the freeliving stages of horse parasitic nematodes. Veter. Parasitol., 73: 257 266.

Knox, M.R., Josh, P.F., Anderson, L.J. 2002. Deployment of Duddingtonia flagrans in an improved pasture system: dispersal, persistence, and effects on free-living soil nematodes and microarthropods. Biol. Control, 24(2): 176-182.

Lyons, E.T., Tolliver, S.C., Collins, S.S. 2011. Reduced activity of moxidectin and ivermectin on small strongyles in young horses on a farm (BC) in Central Kentucky in two field tests with notes on variable counts of eggs per gram of feces (EPGs). Parasitol., Res., 108(5): 1315-9.

Madeira de Carvalho, L.M., Gillespie, P.M., Bernardo, F.A., Farrim, A.P., Fazendeiro, I. M. 2007. Efficacy of the nematofagous fungi Duddingtonia flagrans in the biological control of horse strongylosis in the Ribatejo.
Revista Portuguesa de Ciências Veterinárias, 102(563-564): 233-247.

MAPA - Ministério Da Agricultura, Pecuária E Abastecimento. Equídeos. Disponível em: <http://www.agricultura.gov.br/animal/ especies/equideos>. Acesso em 14 de agosto, 2015.

Milillo, P., Boeckh, A., Cobb, R., Otranto, D., Lia, R.P., Perrucci, S., Di Regalbono, A.F., Beraldo, P., Von Samson-Himmelstjerna, G., Demeler, J., Bartolini, R., Traversa, D. 2009. Faecal cyathostomin egg count distribution and efficacy of anthelmintics against cyathostomins in Italy: a matter of geography? Parasite Vectors, 2(Suppl. 2): S41-7.

Molento, M.B. 2005. Resistência parasitária em helmintos de equídeos e proposta de manejo. Ciência Rural, 35(6): 1469-1477.

Oliveira-Sequeira, T.C.G., Amarante, A.F.T. 2001. Parasitologia Animal: Animais de Produção. Rio de Janeiro: EPUB. 148 Pp.

Paz-Silva, A., Francisco, I., Valero-Cross, R.O., Cortinas, F.J., Sánchez, J.A., Francisco, R., Arias, M., Suárez, J.L., López-Arellano, M.E., SánchezAndrade, R., Mendonza de Gives, P. 2011. Ability of the fungus Duddingtonia flagrans to adapt to the cyathostomin egg-output by spreading chlamydospores. Veter. Parasitol., 179: 277-282.

Silva, B.F., Amarante, M.R.V., Kadri, S.M., Mauad, J.R.C., Amarante, A.F.T. 2008. Vertical migration of Haemonchus contortus third stage larvae on Brachiaria decumbens grass. Veter. Parasitol., 158: 85-92.

Silva, M.E., Araújo, J.V., Braga, F.R., Soares, F.E.F., Rodrigues, D.S. 2013. Control of infective larvae of gastrointestinal nematodes in heifers 
using different isolates of nematophagous fungi. Revista Brasileira de Parasitologia Veterinária, 22(1): 78-83.

Tavela, A.O., Araújo, J.V., Braga, F.R., Silveira, W.F., Silva, V.H.D., Júnior, M.C., Borges, L.A., Araujo, J.M., Benjamin, L.A., Carvalho, G.R., Paula, A.T. 2013. Coadministration of sodium alginate pellets containing the fungi Duddingtonia flagrans and Monacrosporium thaumasium on cyathostomin infective larvae after passing through the gastrointestinal tract of horses. Res. Veter. Sci., 94: 568-572.

Urquhart, M.G., Armour, J., Duncan, J.L., Dunn, A.M., Jennings, F.W. 1998.
Helmintologia veterinária. Parasitologia Veterinária, $2^{\mathrm{a}}$ Ed., Guanabara Koogan, Rio de Janeiro, Pp. 40.

Waller, P.J. 2001. The potential nematophogous fungi to control the free-living stages of nematode parasites of sheep: towards the development of a fungal controlled release device. Veter. Parasitol., 102: 299-308.

Yeates, G.W., Waller, P.J., King, K.L. 1997. Soil nematodes as indicators of effect of management on grasslands in the New England tablelands (NSW): effect of measures for control of parasites of sheep. Pedobiologia, 41: 537-548.

\section{How to cite this article:}

Manuela Colares de Andrade, Emy Hiura, Leandro Abreu da Fonseca, Carolina Magri Ferraz, Caio Colodette Senna, Fabio Porto Sena, Lorena Coutinho Correa, Anderson Rocha Aguiar, Tracy Ferreira Lacerda, Fabricia Molodo Giradi, Jackson Victor de Araujo, Fernando Luis Tobias and Fabio Ribeiro Braga. 2016. Utilization of the Fungus Duddingtonia flagrans in Control of Nematode Larvae Development in Equine Stool. Int.J.Curr.Microbiol.App.Sci. 5(3): 829-835. doi: http://dx.doi.org/10.20546/ijcmas.2016.503.096 